\title{
Up from under: a study of English training on the mines
}

\section{Carol A. Puhl}

A study was done over six months at the training centre of a large mining house, Gold Fields of South Africa. Four instructors taught English courses to experimental groups using an approach integrating suggestopedic language teaching and thinking skills (called henceforth " the integrated approach"). The same four instructors taught English to control groups using traditional methods. English language skills and thinking skills were measured before and after each course. Qualitative data were gathered from learners, instructors and supervisors.

Results clearly showed that black workers with low educational levels can gain an appreciable amount of English in a three-week intensive course. All of the qualitative data and one of the two qualitative measures support this statement.

Further, support was found for greater benefits to the learners of the integrated approach over traditional approaches to language teaching, especially in ability to think and in positive attitudes including self-confidence.

The process of the study yielded additional findings and raised further questions of interest to those involved in language teaching and research.

' $n$ Studie is oor ses maande gedoen by die opleidingsentrum van 'n groot mynmaatskappy, Gold Fields of South Africa. Vier instrukteurs het die geïntegreerde benadering gebruik om ' $n$ Engelse kursus aan eksperimentele groepe aan te bied. Dieselfde instrukteurs het ook die kontrole-groepe onderrig deur gebruik te maak van die tradisionele metodes van taalonderrig. Studente se Engelse taalvaardigheid, sowel as denkvaardighede is voor en na elke kursus gemeet. Kwalitatiewe data is van leerders, instrukteurs en toesighouers verkn.

Resultate het duidelik getoon dat swart werkers met lae opvoedingsvlakke se Engelse vaardighede aansienlik kan verbeter na 'n intensiewe onderrigkursus van drie weke. Al die $k w a l i t a t i e w e$ data en een van die twee kwalitatiewe metings onderskryf hierdie stelling.

Verder is gevind dat die geïntegreerde benadering groter voordele inhou as die tradisionele taalonderrigbenaderings, veral ten opsigte van die vermoë om te dink en van positiewe houdings, insluitende selfuertroue.

Verdere gevolgtrekkings het uit dié studie voortgespruit en kernvrae is ook geopper wat relevant is vir taalonderrig en -navorsing.

\section{INTRODUCTION}

The mining industry is the backbone of most African economic activity in that the export of gold and other minerals generates the main source of foreign exchange and thus forms the basis of trade with the rest of the world. The mining industry in South Africa alone provides $8,5 \%$ of all jobs, and the vast majority of those jobs are held by blacks, from many different countries. According to the 1988 Report of the Central Statistical Service, of the 743065 jobs in the mining industry, 641933 or $86,4 \%$ were held by blacks. For each job one can multiply by 6 to arrive at a conservative estimate of the number of 
people who are dependants of these workers (Snyman, 1989). These jobs also generate foreign exchange for several African countries and help to keep their development process going forward.

Most jobs on the mines can be done by unskilled workers. Adults who have left school even in the first few years may find employment on the mines. The Chamber of Mines estimates that about $80 \%$ of mine workers are functionally illiterate. In recent years mining companies have identified benefits of a better educated work force, and they have taken the position of social responsibility toward their workers. There are efforts to upgrade their work force by specific training and by general education as well, among which language has had a crucial place, specifically English as a second or additional language. Legal reforms in 1988 have removed barriers to employment or advancement based on race. The current thrust of in-house training is to provide a variety of opportunities for workers at many levels to improve their education and skills on a continuous basis.

The need for communication among a multilingual work force has brought the conclusion that ultimately one shared language is needed, and for purposes of intercultural and international communication, that language is English. A further reason for English is that workers have asked for it as a replacement of the pidgin language Fanagalo, which is seen by many to be undignified, or even restrictive and humiliating. Most of the major mining houses are rooted in English-speaking cultures as well. Many black communities seem to opt for English as a Language of Wider Communication (LWC).

\subsection{Statement of the problem}

English functions as an LWC for much of Africa, and a further look at general demographics reveals that there are very few speakers of English as a mother tongue. Virtually all of black Africa has a mother tongue other than English (Lanham \& Prinsloo, 1978). In South Africa, which is home to the largest community of mothertongue English speakers in sub-Saharan Africa, that community numbers 1,6 million, only about $6 \%$ of the country's population. No one language is dominant, with two official and nine officially recognised languages. According to the South African Yearbook 1988/89, Afrikaans, which along with English is one of the two official national languages, has about 2,5 million speakers. There are four black language groups, and each group may contain several languages which are mutually intelligible within that group. The Nguni is largest with 13,6 million mother-tongue speakers. The Sotho group has about 8 million speakers, the Tsonga, 1,2 million, and the Venda, about 500 000. The need of an LWC, which in this case is English, is clear. On the mines, as many as $99 \%$ of those employed do not have English as a mother tongue.

The specific question then arises: How can English best be taught on the mines? Some instruction is available on a released-time basis, for which workers receive full salary; therefore such time must be used to best advantage. It is the central idea of this study to investigate ways to maximize short-term, intensive courses, already a part of training on the mines, to bring about the most language learning possible. If benefits such as greater skill in thinking and more positive attitudes toward self can be achieved, so much the better.

One such gold mining company, Gold Fields of South Africa, approached the Institute for Language Teaching (INTUS), which is known for its innovative language teaching methods, to develop such a course at an intermediate level. The Institute also designed a study to test its own special approach against the intermediate English course that was already in place at the company training center. A range of objective, subjective, qualitative and quantitative data was gathered and examined, and conclusions were then drawn. (Note: The full report is available through the international database of ERIC, 
Educational Resources Information Center, as listed in academic libraries world-wide. It can be obtained also through ERIC microfiche at the Human Sciences Research Council, Pretoria.)

\subsection{Rationale of the study: The integrated special approach}

Language is taught by accelerated methods involving use of physical and mental relaxation, use of specitic kinds of music to widen the perceptual ability of the brain, and use of a specially written story adapted to a particular group of learners with archetypal characters and theme. There is evidence that this approach fosters better learning along with increased self-confidence and self-esteem. Studies by Felix (1988), Odendaal (1987), Botha (1986), and Dhority (1984) among others provide evidence of its efficacy. This approach is based on the method of teaching known as Suggestopedia, which was introduced in South Africa by INTUS in the late seventies and has been successfully used and researched under the leadership of INTUS since then (van der Vyver \& Botha, 1989).

This suggestopedic method was further enhanced by the incorporation of thinking skills into language classes. This specific combination is referred to in the present article as "the integrated approach". Learners can then develop thinking ability in the medium of English, hopefully leading to improvement in both language and cognitive functioning. It is a practical impossibility to separate language and thought, so the connection is a natural one, and it is only made more explicit and systematic by the integrated approach.

The INTUS special approach has been applied, developed, and transformed over several years of practical implementation, and this process is an on-going one. Its utility for many groups of learners has been established, but so far it has not been studied in the context of teaching a second or additional language to adult black Africans in industry with relatively low levels of education. It is necessary to know if it is as applicable as it seems, and to what extent. Besides examining language learning, it is necessary to see to what extent thinking in the new language can be learned. Since all second or additional language learning is cross-cultural, one must determine whether the approach is culturally appropriate in this case. Does it meet the needs of the workers as well as the conditions of training? Then one must decide if it can be extended to other members and groups within this population of learners.

A study was conducted that utilized the integrated approach in experimental groups compared with the company's previous language training course in control groups. With other factors held steady, the design allowed differences deriving from the special approach to be seen and studied clearly. The results seem safely generalizable to at least some other African mine workers with low levels of education and low levels of skill in English.

\subsection{Hypotheses}

Given similar conditions, the experimental groups were expected to make greater gains than the control groups in:

English language skill, as measured by a written test of English, by questionnaire reports of learners, instructors, and supervisors, and by instructor logs and reports.

Thinking skill, as measured by a written test of thinking; by an oral test; by questionnaire reports of learners, instructors, and supervisors; and by instructor logs and reports. Thinking skill in this context is seen as the actual improvement of one's cognitive ability and the 
development of skill in using the second additional language (referred to as L2), in this case English, by means of the language practice gained by practising various thinking tools, which were taught and learned in English.

Attitude, including self-confidence, self-image, and motivation, as noted in questionnaires given to learners and instructors, and as noted in instructor logs and reports throughout the courses.

\section{METHOD OF THE STUDY}

\subsection{Overview of the question}

The question has been raised: How can English best be taught on the mines? Specifically, can adult black workers with low educational levels learn an appreciable amount of English in a three-week intensive course? Does the integrated approach yield greater gains in English, ability to think, and attitude (affective matters) than traditional classroom methods?

\subsection{Selection of subjects}

The company was engaged in training a large number of workers at the first level of supervision. With a choice between administrative officers and team leaders, the choice was made to study team leaders. It was felt that workers in this position were already supervisors, in that their job is to organize work gangs which actually carry out the basic work of mining. Working underground, team leaders and their gangs generally gather and load the gold-bearing rock after it has been blasted loose. Above ground, they may see to maintenance or transportation and the like. When there is chance for advancement, team leaders are likely candidates to move up the ladder. They would be helped by a command of English.

The next step was to determine which team leaders should be chosen. This issue addresses selection and placement of learners in the classes. There were over 5700 team leaders estimated as employed by the company, and evidence gathered from interviews with various training personnel indicated that there was a wide range of background and ability among them. The course that was developed according to the integrated approach, and the control course, were geared for intermediate learners. Two criteria for selection of appropriate subjects (Ss) were then set: evidence of being able to benefit from further training and a command of very basic English. A further consideration always present throughout the study was the effort to make efficient use of information already at hand, and care to have the least possible interference with the company's production.

These criteria were operationalised as scores on tests developed through the Chamber of Mines. A non-verbal test of ability given to all workers, the Industrial Test Battery (ITB), was used, at Stanine 6, to determine ability to benefit from instruction. The test used by the mines to determine literacy and numeracy, the LITNUM, was used to define the level of English. Ss with scores of 14-16 on the English sub-test were requested. Reliability and validity for both tests were acceptable. 


\subsubsection{Basic English: English Proficiency Placement Interview (EPPI)}

It is common knowledge in the field of second language (L2) teaching that learners can know how to read and write, but not speak or listen in the L2, and they can know how to speak and listen fluently but not read or write. Because the LITNUM is a written test, an oral test was needed as well. It would also serve a useful function later in placement.

A five-level scale was devised by Roux and Puhl (1988) specifically for use by Gold Fields Training Services (GFTS). They named it the EPPI, English Proficiency Placement Interview (given in Appendix A). They introduced it to instructors and conducted training in its use for instructors who teach on the mines. It is given in Appendix A. Subjects who scored 3 or 5 on the EPPI were considered to have a basic oral command of English appropriate for the study.

\subsubsection{Summary of selection criteria}

Criteria for learners for experimental and control groups were operationalized as follows:

\section{Ability to learn: ITB Stanine 6}

Command of Basic English: LITNUM English scores of 14 to 16, and EPPI scores of 3 or 5.

Practical difficulties made it impossible to get subjects within set score ranges, however desirable, so the $74 \mathrm{Ss}$ who actually took part in the study are described below. As all team leaders are male, all Ss were male.

These efforts in selection were made also to address the need for homogeneous classes for purposes of on-going instruction, an identified training need.

\subsubsection{Conclusions regarding selection}

1 All the Ss except one had LITNUM English scores of 12 - 20 and ITB stanines of 5 - 9, with half the scores reported at stanine 9. Even when these two scores accompany each other, that is, both in the upper ranges, it seemed not to be sufficient for placement purposes. The qualitative data (below) show that the groups were still not homogeneous enough. Thus a more refined selection procedure, perhaps a test, is needed.

2 The EPPI is not practicable as a selection or testing procedure as implemented by English language trainers without a knowledge of L2 theory and research. The master trainers seem able to use it effectively, but not other persons.

\subsection{Demographics of sample}

A Language Background Questionnaire was developed by Puhl and Roux (in Puhl 1990) and given to each learner in the study. Results below give a picture of the sample group. 


\subsubsection{Place of Origin}

The learners in the study reported that they came from seven main areas in Southern Africa, with the two areas of greatest representation being Lesotho and Transkei. Learners from these two areas seem to comprise half the subjects. Seen in another way, about half are from South Africa, including Ciskei and Transkei, and the others from four bordering countries, Botswana, Lesotho, Mozambique, and Swaziland. If one assumes that the workers from other countries are not likely to know much Afrikaans, it supports the decision of GFTS to press for English as a medium of training and advancement (Roux, 1989).

\subsubsection{Languages}

Consistent with reported place of origin, the two largest mother-tongue language groups are Sesotho (from Lesotho) and Xhosa (from Transkei), making up over $70 \%$ of the sample. The other $30 \%$ are spread over six languages as the mother tongue: Tswana, Zulu, Shangaan, Swazi, Tsonga, "other". No one reports English as a mother tongue.

Multilingualism among black Africans is a well-established fact, and this study bears it out. Of the 74 learners, 68 report a language spoken in addition to their mother tongue. About 1/3 report Afrikaans, Portuguese, or English as the first additional language, and the others report another black language. Forty-six learners, or $2 / 3$ of the group, report a second additional language. Eleven report speaking Xhosa, 11 Sesotho, $10 \mathrm{Zulu}, 8$ English, 3 Swazi, 2 Afrikaans, and 1 Tswana.

A third additional language is reported by 21 learners. The largest number here, 8 , report knowing at least a little English, with 4 each for Tswana and Zulu, and the rest with Afrikaans, Sesotho, and Venda. It seems that 21 out of 74 subjects in the study seem to know something of four languages. This is all the more remarkable when one sees later that half of the subjects in this study are at or below Standard 6 (the eighth year of schooling). While a second or even a third language may be taught at school, many learners have learned without formal teaching. This may show the power of need and practicality in the language learning process.

The fact of multilingualism should also work in favour of English language training. It is commonly held in the field of language teaching that the first additional language is the hardest to learn. Once the learner has figured out, even sub-consciously, how to go about learning a second language, he or she then has developed useful learning strategies which help acquisition of additional languages.

\subsubsection{Age}

The age of this sample of learners as they report it ranges from 20 to 59 years, with the median age of 30 . Half are between the ages of 29 and 34. As a group, the team leaders with some English ability are relatively young.

\subsubsection{Standard of school-leaving}

The median of education as reported by the workers is Standard 6. Some reached Standard 9 (the eleventh year of schooling), the highest reported. Most of these learners came from places where they probably received their schooling in their mother tongue. This makes the challenge of learning English all the greater, and all the more understandable as a study that one is beginning. 
This table indicates that the team leaders in this study are basically a literate group. The usual definition of functional illiteracy is reaching only Standard 4 or below. Yet only $15 \%$ fall into this group.

\subsubsection{Years of service}

Of the 60 who reported years worked on the mines, the median time was 11 years. About half had 10-13 years of service, with only 4 having more than 15 years. By this point, both the workers and the company have invested quite a bit in each other.

\subsection{Instructors}

There were four instructors teaching in the study. The same four taught both experimental and control groups. All were in their 20 's, and all had been employed as language instructors by GFTS for at least a year. All had a tertiary qualification, one an honour's degree. All had attended an intensive week-long training seminar in accelerated teaching methods conducted by INTUS about six months before the start of the study. The Senior Instructor of the four was trained further by UPTTRAIL ${ }^{1}$ in a three-week seminar in the teaching of thinking, and she communicated the main ideas and thinking skills to other members of the instructor team.

This study formed part of their practice teaching for earning their certificate as teachers of the integrated approach used in the experimental groups. The instructors taught both control and experimental groups, thus eliminating the variable of different teachers as a confounding influence. They alternated their teaching in the study, teaching for three weeks, doing other work, teaching three weeks, etc. One instructor was responsible for one group; however, they have always worked together as a team, and they continued to do so in this study. Thus effects cannot be attributed to any one instructor.

In summary, it can be said that all of the instructors were trained by INTUS and UPTTRAIL in using the integrated approach, and were developing their skill in it by means of teaching courses in this study.

\subsection{Treatment of experimental and control groups}

A total of eight alternating three-week intensive courses were given at the GFTS centre at Kloof Mine from July to December 1988. The courses were alternated so that any effects generated by events or circumstances external to the courses could be spread over both control and experimental groups. Two groups were taught simultaneously, and to avoid the inevitable comparisons and possible feelings of envy, these two groups would both be control groups for three weeks, then they would both be experimental groups for three weeks, alternatively. Classes were held for 35 hours per week, for a total of 105 hours of instruction. Time needed for pre- and post-testing was included in the 105 hours. All of the subjects had similar lodging arrangements, similar food, and classes at the GFTS training centre. With the same instructors, the only difference was the teaching method or approach.

$1 \quad$ UPTTRAIL stands for " Upgrading of Teaching, Training and Learning". It is a private trust dedicated to the improvement of primary education, especially in black schools. 
Both experimental and control groups were taught English as an L2 at a low intermediate level. The main emphasis was oral ability, with some reading and writing, spelling, and basic principles of grammar. Elementary social skills were included. Both groups received good language teaching, using about the same games, materials, posters, flash cards, and dramatizations. Both used physical relaxation techniques, and both were unconventional in that learners were active, sat on the floor for some activities, and were taught interactively. Both were assigned homework, the experimental group completing thinking problems, and the control group completing English assignments.

\subsubsection{Method used for experimental group}

The integrated approach was used (mentioned earlier in this report). One can say that it is an adapted and enriched suggestopedic approach. The course was given in a specially developed and well-equipped room, as required in this approach. The room was curtained and carpeted, with overhead projector and built-in screen. Each learner had a large comfortable chair. There were activity areas, extra materials, posters on the walls, a wide range of stimuli on the periphery of the class (hence called "peripherals"). Because music is used at certain times in the special cycle of teaching activities, a high-fidelity record-tape player was essential. In all, the room projected a homey, interesting, and encouraging atmosphere.

As required by the approach, materials were specially created for workers on the mines who are learning English at a low intermediate level. The text, THE WAY TO THE HEART, was developed by the instructors. It is the story of Henry, who finishes matric, looks for work on the mines, and becomes one of the first black recruits for Industrial Relations Assistant. Henry has a range of friends on the mines, including shift bosses and team leaders. He plays soccer and finds a girlfriend. In the process, Henry also learns some skills of thinking. Henry, like all of us, is engaged in a search, and in many ways his search is one with which these learners can identify. The thinking skills were embedded in the story and taught implicitly as part of the language programme. Supporting materials, such as posters and handouts, were also developed.

To explain in more detail, the integrated approach at GFTS was organized around the following cycle: physical relaxation, mental relaxation, activations, and the concert session. Physical relaxation exercises improve deep breathing and blood circulation, and they assist concentration, bonding of people in the class, and creation of a positive atmosphere. Mental relaxation, using baroque background music, consisted of an activity such as remembering an early pleasant learning experience, imaging a visit to a favourite spot, or guided imagery through some of the text.

Next in the cycle came activations, such as dramatizations, language games, and songs, which "activate" or help the learner use and internalize more strongly the language material which has already been read and understood. The concert session is the input phase of the next act in the text. The instructor read the new act first to the accompaniment of classical music, and read it again to learners in a relaxed state to the accompaniment of baroque music.

The embedded thinking skills were also taught explicitly in the L2 as a component of the language curriculum, and part of language practice took the form of problem-solving in the L2. The inclusion of thinking skills makes the integrated approach unique and something new in its own right in the field of L2 teaching. The explicit teaching of thinking skills took place in a more traditional class venue.

There are many ways to break down thinking skills into teachable units, and the way utilized here is based on the Cognitive Research Trust (CoRT) of Dr Edward de Bono (1986). The theory behind the CoRT programme is explained by de Bono (1976). Six skills are taken from his first set, Cort 1, and his famous Six Thinking Hats were taught 
(de Bono 1985). The skills were: Positive-Negative-Interesting (PNI), Consider All Factors (CAF), First Important Priorities (FIP), Aims, Goals, and Objectives (AGO), Consequences and Sequels ( $C \& S$ ), and Other Person's View (OPV). The skills are more fully explained in Appendix B, "The Teaching of Thinking" (Capdevielle, 1988). Effects of the CoRT programme have been shown by Edwards (1988) and Edwards and Baldauf (1987). A fuller examination of the teaching and thinking is found in Nickerson, Perkins and Smith (1985).

\subsubsection{Method used for control group}

The venue was a modern classroom for adults, with carpeted floors, curtains, moveable tables with padded chairs, an overhead projector and built-in screen, and a hi-fi recordtape system. The colours were muted and soft on the eye. Posters for teaching were on the walls, and instructional support materials were there also. The room was pleasant though still a classroom. Classical music was used at times as background, especially when students were doing writing work. Some instruction took place in a language laboratory.

The materials were taken from three main sources, COURSE FOR ADULTS IN READING AND WRITING, START WITH ENGLISH, AND SPEAK BETTER ENGLISH.

The COURSE FOR ADULTS IN READING AND WRITING (CARW), of the Department of Education and Training, has as a main objective the teaching of very basic writing. It includes word knowledge, grammar, structures. Parts of it were selected for class use.

START WITH ENGLISH provided grammatical practice exercises from which instructors selected as needed.

SPEAK BETTER ENGLISH is a commercially prepared book and tape course with good quality sound and excellent English pronunciation as a model for learners. It is the story of Mr. Lourens, who arrives at Heathrow, goes to London, and experiences a hotel, a bank, and restaurants. He travels around, meets various people, shops, buys clothes, visits a museum, and has a run-in with police. Language activities are built around his adventures.

The control group, like the experimental group, attended class all day, and an active, interactive approach was used; it would have been impossible to use a lecture approach for this amount of class time daily.

\subsection{Measuring Instruments}

Both quantitative and qualitative data were obtained.

\subsubsection{English language skill}

The EPPI, used for selection of Ss, was also scored according to the Carroll scale (Appendix C) as a pre-test measure of oral English skill. It thus served a dual purpose before the course. It was given at the end of the course, this time scored only according to the Carroll scale.

English language skill in written form was measured using the BALT B as a pre-test and as a post-test. The English sub-tests of the Basic Arithmetic and Language Test Battery (BALT B) developed by the Chamber of Mines (1975, revised 1985) were used as a 
written pre-test and post-test. There are 20 items of vocabulary, 20 of usage, and 15 of comprehension, for a total of 55 items. All of the items in English are multiple choice, with five choices of response. It is designed to test English as an L2. According to the GFTS summary of "Skills Tests and Levels of Available Language Tests," the vocabulary section tests knowledge of meanings of words along with ability to relate two similar meanings. The usage section tests ability to use grammar principles to form correct simple sentences. The comprehension section tests ability to understand the content of a passage of continuous prose.

\subsubsection{Thinking Skill}

Thinking skill was measured by the ITB given after the course. The ITB was used for selection and as a pre-course measure. As the learner already had an ITB score generated within the preceding year, and as general ability tests have been shown to reflect gains when thinking is explicitly taught, it seemed reasonable to use such a test as a post-test. A further reason supporting this decision is that ability tests are considered to hold constant for about three years without direct teaching of thinking. Its range of possible scores seemed to allow for perceptible gains, and the fact that selection was to be made of learners in Stanine 6 allowed room for improvement. Also, a new form was being developed, but it turned out not to have been available for use as yet.

\subsubsection{Questionnaires and logs}

Post-course questionnaires were given to learners, instructors, and supervisors. These questionnaires were essentially the same, with adaptations appropriate to each group. Responses were sought regarding perceived post-course changes in English language skill, thinking skill, and affective variables. Instructors were asked to keep logs of their responses for each day.

\section{RESULTS AND DISCUSSION}

\subsection{Oral skill in English}

A sample of English before and after the course was recorded on audio tape from 52 learners. The point of the interview was to have the learner show how much oral English he could handle comfortably. The full procedure is given in Appendix A.

Tapes were scored jointly by two scorers trained in use of the Interview Assessment Scale by Carroll (1980), given in Appendix C. Scorers were not told which tapes were pre- or post-tests. The range of scores was expressed in bands from one to nine, with plus signs used to indicate half a band. Data from eight Ss was suspected to have been labeled incorrectly, in favour of the experimental group, and the conservative decision was made to omit this data.

That left an experimental group total of 31 and a control group total of 13 . Results are given in Table 1. 
Table 1: Analysis of interview scores (Carroll's Bands)

\begin{tabular}{|ccc|}
\hline Number of Learners & Experimental Group (n=31) & Control Group (n=13) \\
\hline $\begin{array}{c}\text { No. of Scores that } \\
\text { increased } \\
\text { from pre- to post-test }\end{array}$ & $\begin{array}{c}26 \\
\text { Net gain: } 35,5\end{array}$ & 13 \\
\hline No. Decreased & 3 & Net gain: 14 \\
\hline No. Same & 2 & 0 \\
\hline
\end{tabular}

Table 1 shows an increase of about one band per learner. The experimental and the control groups both clearly show a benefit to learners of receiving classes in English. Furthermore, the gains in the experimental group are numerically higher than those in the control groups.

T tests were carried out to determine whether these gains were statistically significant. The increase in both groups was statistically significant, with $t=4,91$, $p$ less than, 001 , df $=30$ for the experimental group, and $t=6,80, \mathrm{p}$ less than .001 , $\mathrm{df}=13$ for the control group. The difference in gains between experimental and control groups was not statistically significant, with $\mathrm{t}=1,02, \mathrm{p}=, 40, \mathrm{df}=40$. However, the experimental group gained numerically more on average than the control group, in the expected direction.

\subsection{Written skill in English}

The means on the BALT B for the experimental and control groups on the pre-tests were compared by a t-test and, as no significant difference (NSD) was found, the two groups were considered theoretically equal at the start of the course. A d-score was found for each subject by subtracting the pre-test score from the post-test score. Each dscore represents the gain (or loss) over the course, as measured by the BALT B language sub-test. The mean of the d-scores for the experimental group was compared with the corresponding mean for the control group, by a t-test, with NSD.

In fact, the d-scores for both experimental and control groups were negative ( $-1,4$ and 1,1 respectively), indicating a decrease on the BALT B sub-test. This result is suspect, being inconsistent with results on the oral test and with reports from learners, instructors, and supervisors. For this reason, data tables are not presented.

\subsection{Thinking: ITB}

The Industrial Test Battery, described earlier as a selection test, was used as a post-test of thinking skill. As for the BALT B, a comparison of pre-test means showed NSD, indicating that both experimental and control groups were theoretically similar at the start. A difference score per learner was calculated, and the mean of the d-scores for experimental learners was compared with the mean of that score for control learners by a t-test. NSD was found. However, gains were noted for both groups. This result provides some evidence that thinking was better after the course. 


\subsection{Results and discussion of learner questionnaires}

Twenty-five questionnaires were returned from three of the four experimental groups. Sixteen questionnaires were returned from three of the four control groups. The 25 were analyzed as a whole, and the 16 were analyzed as a whole. Results were then compared.

The learners did not always answer the question, but often wrote whatever they had to say, relevant or not. All comments were considered important and were included in some way. The very fact that a response was written down by at least one learner indicates that the idea was in the group, and chances are good that this one learner speaks for at least some others. One gets the impression that learners worked hard to express themselves. Interpretation of poor handwriting and imperfect English were difficulties, but the message usually came through. Some questionnaires were only partially completed.

\subsubsection{The learners as a whole: both experimental and control groups}

In general, the learners in both experimental and control groups were very positive about their three-week experience. They all liked learning English and want more of it. They liked their teachers and the conditions both in class and in their accommodations. They expressed appreciation to their teachers and to Gold Fields (GF). Loyalty to GF is evident, with one proudly defending his English course, another persuading a friend to stay at GF, and one making suggestions for greater productivity. They felt they could think better as a result of either course; they seem to have been stimulated and broadened, encouraged to somehow become better. They are definitely ambitious, looking for what will come next, hoping for promotion, wanting a better salary and a better future. While they have a strong motivation to learn, they do not seem to know what steps they can take to better themselves.

The motivational effects of simply learning can be seen in their feedback. They seem to feel better about themselves only by taking a course, by applying themselves, by expanding their skills. Their attitudes, confidence, and self-image seem to have improved. One suspects that being so well treated also contributed to improved selfimage.

One is struck by their feelings of community, with the "black nation," with GF, with their children and the future, and with others, to whom they want to extend the benefits of the course. There seems to be a very democratic spirit. They seem to be studying black-white contact, perhaps with an eye to a non-racial future. They express the need for more feedback on their progress.

\subsubsection{Experimental group vs control group}

Many of the results here were unexpected. For example, self-image was expected to improve in the experimental group, and it seemed to, but it also seemed to improve in the control group. The experimental group was expected to be more positive, but they were both quite positive. More vitality in the experimental group was not expected, but there is strong evidence of it.

From the responses on the learner questionnaires, one gets an overall image of the control group as appreciative of an educational experience in English. With small groups and good teachers, they feel things are fine, similar to though greatly improved over a regular school experience. They accept the course gratefully and want more. They are uncritical, nicely co-operative, almost passive. 
A different picture of the experimental group emerges. One can imagine it to be a spirited horse, lively and eager in its traces. These learners asked more, and more difficult questions: why, where, what would happen IF. They made suggestions for improvements of their working conditions. They seemed to respond to the questions with more elaborate answers, giving support to what they said. In short, they seemed to be thinking. There was energy in what they said; they seemed to have been reached. They tended to answer the questions more directly than the control group. They also gave more negatives. One got the feeling that they reached into themselves and gave more, and also that they would be harder to control, not an unusual consequence of thinking. There is a dimension in this group that was missing in the control group. Since the groups differed only in method of instruction, it is not unreasonable to attribute the difference in large part to the method.

The experimental group responses included several comments on the method, all spontaneous and all positive. To the control group, method seemed invisible, expected as part of a class.

The experimental group expressed unhappiness and even frustration with placement. They did not like being in a group where others knew much more English, and felt sorry for those who struggled a lot. The control group said nothing about placement.

\subsection{Results and discussion of questionnaire for instructors}

Results were tabulated by question for the experimental and then for the control group. The discussion follows.

There were several responses common to both experimental and control groups. In general, students were enthusiastic and more confident. The instructors were thoughtfully critical of course material, always trying to make it better. This is the mark of good professionals. Instructors are still developing ease with the method and with thinking skills.

There were several differences. In general, instructors seemed to feel it was easier to present the control than the experimental course, in that not so much was demanded of the teacher, but then it could be boring and at times they felt not so close to the students as in the experimental method.

Instructors did not feel so different after either course, a bit tired and negative, but much more negative after control courses.

Some instructors liked the change from one type of course to another, which indicates that a break from one set way might be catered for. However, some people in general do not like to change so much, and this should be at the option of instructors rather than imposed.

There were differences in instructor reports of student response. In the experimental group, students were enthusiastic with just a few remaining uncommunicative. In the control groups, the tone was more negative than positive, and less was demanded of the students and less received.

Instructors generally felt that the language improved. The experimental instructors were sure that student oral skills were better, while the control instructors were not so sure, though they thought reading and writing might have improved.

Instructors felt that thinking skills in the experimental groups very definitely improved. In the control groups, one group improved in general.

Attitudes in the experimental group were reported as very positive; for controls, some positive, others no difference. 
Improvement of self-image was reported high for experimentals, but slight or no change in controls.

One cannot help getting the impression that the experimental groups were generally lively, positive, and colourful, while the control groups were generally fine, plodding along. There seemed to be an important dimension present in the experimental groups that was missing or at least greatly reduced in the controls.

Such a dimension is very difficult to quantify, yet it is what distinguishes excellent teaching. The teacher must reach the students deeply, must invite their response and value it on many levels, and motivate them to go further on their own. No method can guarantee this kind of teaching, and it can be developed without this method, but it seems that the experimental approach creates the climate that is necessary for it and makes it easier. In traditional teaching, factors that could be used remain neutral, and such excellent teaching is not so likely to happen. The present study bears this out.

\subsection{Results and discussion of instructor logs}

The logs, developed by Roux (in Puhl, 1990) were completed by the instructors daily in the first two experimental courses and the first two control courses. Some items were left blank. The overall evaluations are given in Tables 2 and 3.

Table 2: Overall Evaluation of the Day (experimental group instructors):

\begin{tabular}{|cccccc|}
\hline Inspiring & Good Average & Bad & Uninspiring \\
0 & 17 & 20 & 1 & 0 \\
\hline
\end{tabular}

Table 3: Overáll Evaluation of the Day (control group instructors):

\begin{tabular}{|cccccc|}
\hline Inspiring & Good Average & Bad & Uninspiring \\
1 & 9 & 28 & 0 & 0 \\
\hline
\end{tabular}

The teachers seemed to think the experimental materials were slightly better than the control materials. This is especially true of the supporting materials, and of the activations/exercises, even though it was reported that the same ones were used for both experimental and control treatments. Perhaps the context of the treatment, that is, the experimental approach, made a difference in the way the exercises were experienced. If so, then the approach is successful, as one of the things that it does is to set an overall positive climate.

The student response was very similar to that of the teachers. One cannot escape this if one asks for teacher perceptions, so it is not surprising. The students were seen to respond positively to thinking skills, most good and some average. One might infer that their response reflected that of the teachers.

In overall evaluations of the day, both groups had an average-to-good response. For the experimental group, however, the ratings were closely divided, and in the control group, 
only one-fourth of the days were rated good and three-fourths, average. Given that the same teachers were teaching both ways, they seemed to find the experimental approach much better than the control approach. This is an important finding.

In both experimental and control, learners in general moved from being difficult in the beginning to being active and successful. Overall, however, the evidence is clear that, with the possible exception of the text, the learners preferred the experimental materials and exercises to those in the control group. They liked learning English, but the experimental way is better appreciated and got more of a positive response from learners and students alike.

\subsection{Checklist for supervisors}

The language instructors wanted to have more feedback on their courses, and they created a Checklist for Supervisors. Consequently the checklist was sent to supervisors of the team leaders they had taught in the course. Of the 74 students who had come onto the courses during the six months of the study, checklists for 13 students were returned. Four questions were relevant to the present study.

The supervisors felt in general that the learners had improved in oral and written English. There is still room for more improvement, which is expected because the learners were at the intermediate level. Two comments refer to an improvement in selfimage and attitude. This feedback is encouraging because a major purpose of training is to improve the team leaders' performance on the job, and this goal seems to have been well accomplished.

\subsection{Discussion of problems with the study}

Research in the real world rarely proceeds perfectly, and several operational and methodological problems were encountered. It seems useful to examine them, because they could also have contributed to the specific results obtained in this study, and also as learnings that are important for future research of this type.

\subsubsection{Operational}

1 Numbers of Ss in the final analysis were quite small $(n=18$ and $n=20$ ), perhaps too small for statistical effects to show up.

2 Some data could have been faulty. When one thinks of all the steps it has gone through, from ITB testing on the mines, hand scoring, recording in files, removing from files and recording on a paper, recording on a data capturing sheet, and then entering into a computer, there are so many chances for human error. Several errors were in fact found, including some in which scores exceeded the possible range. One wonders how many others have occurred that were not obvious. It could take only one error to alter the means and difference scores significantly.

3 The tests perhaps were not fine enough to measure gains over a short period.

4 The tests may not be appropriate for measuring gains. Both the ITB and the BALT B were developed as selection and placement tests, not as proficiency tests. The use of such a test to measure gains has not proved fruitful in general, according to Dr Kyle Perkins (1990), a world authority on L2 testing. They still may be tried in the future for these purposes, but only along with other more appropriate tests, and only with a much larger sample of learners. 
The BALT B may not have been appropriate in that its sub-tests were the usual vocabulary, usage, and comprehension. The experimental course was not geared to teach usage or reading comprehension in that sense. Actually, the control course was geared in this direction, and the test seemed biased in their favour, but this result did not occur.

Another indication that the BALT B was not functioning properly for whatever reason is the fact that, for both control and experimental groups alike, the difference scores are negative. A decrease, even though not at a level of significance, is hardly to be expected after three weeks of intensive training. This decrease contradicts other results and it seems reasonable to treat the BALT B results with scepticism.

\subsubsection{Methodological}

Several methodological problems have been noted, reasons that quantitative differences were not found.

1 First, the same teachers taught both control and experimental groups. This was a necessary situation because there simply were no other language teachers, and because the study was the practical part of their training for certification. However, once a teacher has taught with the integrated approach, that teacher may well be different, seeing broader and deeper aspects of the teaching-learning process. How then can one teach and not utilize these intuitions? Results that are now coming out of other major research conducted in conjunction with INTUS, especially the UPTTRAIL project, support this explanation.

Actually, while one would like to establish significant quantitative differences, the fact that they did not appear might support the strength of the experimental teaching approach. It is not something that can be turned on and off, but it becomes part of one's self as a teacher. If this is the case, it is indeed a good result.

2 By their own report, the instructors were still not quite sure of themseives when utilizing the integrated approach. It could then be that the approach was not fully used, and thus that the treatment itself as implemented was diminished.

Both of these methodological aspects could have served to make the experimental and control treatment too much alike for valid comparison. In this case, no significant differences could be expected.

3 A third reason might have to do with treatment of the groups as it was described. The instructors used many aspects of the integrated approach when teaching the control groups. They used about the same posters, flash cards, dramatizations, games and teaching cards. While good teachers may use these techniques, to use the same ones may have worked against the study. It seems safe to say that it is not usual in L2 teaching to incorporate relaxation techniques or to play classical music, both of which the instructors did in the control groups.

$4 \quad$ The fact that none of the instructors had qualifications as a teacher of any second language may have affected the research negatively. They were expected to teach control groups by traditional methods when they could not have really known traditional methods. Wanting to teach well, in a professional spirit, they drew on the only real training they had, in the integrated approach. This seems another reason that the difference between experimental and control treatments was reduced. 
According to research methodologist Lipsey (1990), the experimental/control paradigm itself with its statistical testing may not be sensitive enough to record very real changes that do indeed take place in an educational setting.

The time period could have been too short to allow the effect to become strong enough to be detected by traditional measures.

The inappropriate utilization of experimental techniques, if not of the whole method, in control groups indicates the power of the experimental method. It seems as if the instructors couldn't help but give their best to their students. It may be an impossible task for instructors to teach both control and experimental groups. It seems clear that instructors must not be put in this position again.

It can be noted that in another INTUS project to train language instructors, the instructors did not want to teach control groups and students did not want to study in them. Instructors at GFTS were not enthusiastic about control group teaching, but they did as they were asked, in a spirit of co-operation. An important lesson has been learned here.

\section{CONCLUSIONS AND RECOMMENDATIONS}

\subsection{English language skills}

English language skill improved for both experimental and control groups, as measured by four out of five measures. The oral test, the questionnaire reports of learners, the questionnaire reports of instructors, and the checklist of supervisors all show gains in English. Statistical tests on the oral measure were significant for both groups. The experimental group had a higher average net gain on the oral measure than the control group.

On one measure, the BALT B, results were negative rather than positive for both groups. As discussed earlier, use of the test is suspect.

Every learner questionnaire indicated that English skills improved. Instructor questionnaires also said this, except for one control group, where the instructor was not so sure. For the control group, instructors generally felt that reading and writing improved more than speaking. Supervisors also generally agreed that English skills improved.

While virtually all the learners improved their English language skills, it cannot be said that the experimental group made greater gains than the control group regarding English language skills. The pattern of results was similar for both groups, with possibly the experimentals doing more in oral skills and controls doing more in written skills.

The hypothesis of greater English language skills gained by experimental learners is partially confirmed.

\subsection{Thinking skills}

A clear difference emerges between the experimental and control groups on thinking skills, as reported by the instructors and the students. Instructors say the students in the experimental group "definitely" improved their thinking skills, while the majority say there was no improvement in thinking skills in the control group. All of the students in the experimental group, and all but one in the control group, said they felt that their thinking skills improved. However, the control group did not elaborate, but the 
experimental group had a lot to say, giving some of the tools they had learned, and adding several comments about when they think and what they think about. By their very elaboration they are giving evidence that they think better.

Instructor logs and reports and supervisor checklists did not in the end include comparative data on thinking, so no conclusions can be drawn from these sources. Use of the ITB is suspect.

The hypothesis that experimental groups would show greater gains in thinking than control groups is partially confirmed.

\subsection{Attitude}

Attitude (including self-confidence, self-image, and motivation) was not tested quantitatively because appropriate tests are not available. Qualitatively, attitude differences can be seen in questionnaires returned by students and instructors, in instructor logs and reports, and on the checklist for supervisors.

Learners in both groups, according to their questionnaire reports, generally were grateful to GFTS and to their instructors for the course and for the "VIP" treatment. They felt empowered because they had learned. They felt encouraged to carry on, to "face the future." They felt better about themselves. They felt motivated to keep on learning English. Their responsiveness and their confidence improved.

The groups showed important differences. The experimental group showed more vitality, while the control group seemed more passive. The experimental group seemed more critical and thoughtful than the controls, and they voiced frustration with their placement, while the controls were silent about placement.

On instructor questionnaires, differences emerge. Instructors saw the experimentals as much more positive as a result of the course. One control instructor felt there was no difference, not even self-confidence.

Regarding self-image, instructors felt that experimentals improved and controls did not, or only slightly. Instructors said that experimental group learners were much more confident, control group learners only slightly more, if at all.

Findings on positive attitude seem ciearly related to the the integrated approach.

The hypothesis that experimental groups would show greater improvement on attitude than control groups is confirmed.

\subsection{Final observations and recommendations}

* The integrated approach seemed to bring about more oral language acquisition and more active thinking in the experimental group. Also, the learners enjoyed it. The approach seemed to bring about more positive attitudes and better selfimage.

* Learners in the experimental group seemed to like their materials and exercises better than learners in the control group.

* Instructors seemed to respond better to the integrated approach than to the control-group approach. They rated about twice as many teaching days as good, compared to the control group. 
The method seems enjoyable to the learners, and thinking skills can be incorporated into many training efforts such as lectures on mining, for example. The improved speaking, thinking, attitudes and self-image of the learners using the integrated approach indicates valuable benefits to the company.

* There is potential and ambition in this group, and it may be found in other groups within the work force. It must be identified and developed, for the workers, for the company, and for society.

Employees need to develop better cross-cultural competencies for job-related interaction. Cultures have differing beliefs, value, behaviours, and ways of interacting that transcend language. Seeing others only from one's own cultural frame of reference can result in big and often unnecessary problems. The "fresh" behaviours of some learners seems a good example.

The experimental group indicates that such training is possible and that positive benefits can be realized. Such teaching must be explicit so that learners can retrieve a skill and apply it to new situations as they find it useful to them. They must know the skills, and also at the level of meta-cognition, they must know that they know.

* The idea of community as motivation within the work force should be further explored.

Motivation concerns why people do what they do. Why do employees come to work every day? Obviously they come to get a pay check. Certainly true, it is not the only reason. Other reasons can be seen when one asks: Why do people change jobs? For pay of course, but after that may come quite a list of reasons, including benefits and working conditions. Working conditions generally include the people one works with on a day-today basis, and may include the meaning a person feels in a particular job within the organization.

One could not help but note the sensitivity of the students to other people, not just to their bosses but to their peers and others within their societal reach. One typical learner comment:

"I want to go help other people at work and teach them English and other things I know".

This feeling of oneness with others, or community, is a powerful force that could be channelled into educational matters, as the quote also shows.

There can be study groups, reading groups, library groups, small after-hours educational groups on almost any topic. Learners can help one another, as in peer tutoring, and encourage one another, as in taking a course together, getting to classes, and doing homework. This could happen with minimal cost to the company, though some structure and leadership are required. The idea of working to improve one's self for the sake of others, versus working to get ahead of others, seems to emerge from the data and may be a useful learning for the improvement of both workers and company.

\section{NOTE}

The author extends special thanks to:

Prof. J.C. Roux (Department of African Languages) who served as project leader;

Mr K. Gericke and his team at Gold Fields Training Services, who gave their full cooperation; 
Dr D.H. van der Vyver, who initiated the project;

Mr C.J.J. Snyman, who provided special support and consultation.

\section{REFERENCES}

Basic arithmetic and language test battery (BALT B). 1985. Johannesburg: Chamber of Mines of South Africa. (Original version, 1975)

BOTHA, H. L. 1986. Suggestopaedia for second language acquisition. University of Stellenbosch: Unpublished D.Ed. thesis.

CAPDEVIELLE, B. 1988. Course notes.

CARROLL, B. J. 1980. Testing communicative performance. Oxford: Pergamon Press.

DE BONO, E. 1986. CoRT Thinking, Series 1. New York: Pergamon Press.

DE BONO, E. 1986. CoRT Thinking, Teacher's Notes. New York: Pergamon Press.

DE BONO, E. 1985. The six thinking hats. New York: Pergamon Press.

DE BONO, EDWARD. 1976. Teaching thinking. New York: Penguin Books.

DHORITY, L. 1984. Acquisition through creative teaching. Sharon, MA: Center for Continuing Development.

EDWARDS, J. 1988. Measuring the effects of the direct teaching of thinking skills. University of North Queensland (Australia): Unpublished paper.

EDWARDS, J., \& R.B. Baldauf, Jr. 1987. The effects of the CoRT-1 thinking skills program on students. In D. Perkins, J. Lochhead, and J. Bishop (Eds), Thinking: the second international conference. Hillsdale, New Jersey: Lawrence Erlbaum, 453473.

FELIX, U. 1988. The effects of music, relaxation and other suggestopedic elements in a primary school German class. An experimental investigation. Per Linguam, Vol. 4, No. 2.

LANHAM, L. W., \& K.P. Prinsloo. 1978. Language and communication studies in South Africa. Cape Town: Oxford University Press.

LIPSEY. M.W. 1990. Design sensitivity: statistical power for experimental research. Newbury Park, CA: Sage Publications.

NICKERSON, R.S., D.N. Perkins and E.E. Smith. 1985. The teaching of thinking. Hillsdale, New Jersey: Lawrence Erlbaum Associates.

ODENDAAL, M. 1987. Raising achievement levels by means of Suggestopedia. Per Linguam, Vol. 3 No. 2.

PERKINS, KYLE. 1990. Personal communication. Stellenbosch.

PUHL, C A. 1990. Up from under: English training on the mines. Full report. Educational Resources Information Center (ERIC) database. Washington, D C: Center for Applied Linguistics.

ROUX, J.C. 1989. Personal communication.

ROUX, J.C. and C.A. Puhl, 1988. English proficiency placement interview (EPPI). Stellenbosch: Institute for Language Teaching, University of Stellenbosch.

SNYMAN, G. J. J. 1989. Medium-term Forecasting Associates, Building Economists. Personal communication. Stellenbosch. 
SOUTH AFRICA 1988/89: Official Yearbook of the Republic of South Africa, Fourteenth Edition. Pretoria: Bureau of Information.

SOUTH AFRICA STATISTICS: 1988 Report. Pretoria: Central Statistical Service.

VAN DER VYVER, D. H., \& H. L. Botha. 1989. The implementation and evaluation of suggestopedic/SALT language teaching in South Africa since 1984. Pretoria: Human Sciences Research Council, Unpublished report. 


\section{APPENDIX A}

\section{ENGLISH PROFICIENCY PLACEMENT INTERVIEW (EPPI)}

This scale has been developed by J.C. Roux and C.A. Puhl through the Institute for Language Teaching, University of Stellenbosch, specifically for mine workers. It was adapted from the General Assessment Scale of B. Carroll, TESTING COMMUNICATIVE PERFORMANCE, Pergamon Press, 1984.

WHAT: The English Proficiency Placement Interview (EPPI) is a way to determine a person's skills in listening and speaking in English. After the interview, the interviewer makes an informed judgement or assessment of oral English skills according to a given five-point scale.

WHY: The only purpose of the interview is to serve as one factor among others for placing learners in classes appropriate for their skill level. People learn more when they are taught together with others at the same level, and the EPPI, along with the Industrial Test Battery (ITB) and Literacy and Numeracy Test (LITNUM), is designed to help identify learners who have the same level of skills, and thus about the same level of needs, in English. It is necessary to have an oral test because a person can be good at written skills in a language (reading and writing) and still not be good at oral skills (listening and speaking), and vice versa. The lack of a clear relationship between oral and written skills makes the EPPI necessary for homogeneous grouping.

WHERE: The EPPI can be given on the training site of each mine. A comfortable setting is desirable.

WHEN: Because it is brief, the EPPI can be given before or after the learner is tested on the ITB, LITNUM, or BALTB (Basic Arithmetic and Language Test Battery). It can also be given before or after his work shift, or at another time when the learner is available. It should not be necessary to have the learner miss work for this interview.

WHO: The EPPI is appropriate for any adult for whom English is not the mother tongue.

HOW: The interviewer must have some training in conducting the interview. Basically, he or she must converse with the learner so that:

(a) communication takes place, and

(b) the learner gets a change to give enough of a sample of his English so that a judgement or assessment can be made. A few minutes is usually enough.

Some questions are suggested to help get started in the interview, but these questions are not really necessary as long as there is conversation. The specific content is not so important. Communication that elicits talk is what is wanted. If the learner offers a comment or information, it may be useful to follow up on this topic.

Two major concerns in any test are reliability and validity. A test is reliable if it gives consistent results. For example, if two judgements of the same learner vary widely, and if this happens too often, then the test is not considered reliable. A test is valid if it measures what it is supposed to measure. For example, if a test is supposed to measure oral skill but is given in writing, then it is unlikely to be a valid measure of speaking. In an oral language test, the training of interviewers usually improves reliability to an acceptable degree, and the type of interview, if straightforward, will show face validity to an acceptable degree. 
Points for interviewer in conducting the interview:

(a) The learner will probably be very nervous. Be warm and friendly, chat with him, help him relax. He may not know why he is being called in. It often helps if you explain to him that the purpose is to find out his level of English so that he can attend classes with the group that is right for him. The interviewer should avoid writing.

(b) Be careful to follow the criteria for each level as closely as possible. Try not to let your liking or your dislike of a person influence your judgement of his oral skills in English.

(c) It may be helpful to interview in the form of a group conversation, so that the learner does not feel so much "on the spot". One can have two learners, two interviewers, or other people present and participating in the interview. If a learner is too quiet, one can always direct questions to him to elicit talk.

(d) Remember that you are engaging in human interaction. Be kind and respectful of the person at all times, and try to help him not to feel inadequate. We all are very ego-sensitive when we speak in a language other than our mother tongue.

(e) Such interviewing is hard work. You must draw out the learner if necessary, and you must be making judgements on proficiency. Do not schedule too many people at any one session. Give yourself some break time.

(f) It may help you, especially when you are new at giving this interview, to work together with a colleague. You can then discuss the interview and arrive at a joint judgement.

(g) If a person does not respond, try to give him some prompts. Do your best to elicit talk. However, if things become tense or difficult, than discontinue the interview.

(h) A note of caution: Be careful of making judgements that are hasty. Even an experienced interviewer must give the learner sufficient speaking time for arriving at a good assessment.

\section{POSSIBLE INTERVIEW QUESTIONS:}

1 (Greeting) How are you today? Etc.

2 (Home) Where are you from? Does your family live there? Are you married? Children? Etc.

3 (Job) How long have you been working here? What work do you do? Etc.

4 (Goals) What are your future plans? When does your contract finish? When will you go to (place he is from)? Etc.

5 (Interests) Do you like sports? Which ones? Do you like to play any sports? What is your favourite team or sports person? Etc.

6 (Open-ended) Is there anything you would like to ask me? 


\section{ENGLISH PROFICIENCY PLACEMENT INTERVIEW (EPPI) SCALE}

Level 9. EXPERT USER. Communicates with authority, accuracy, and style. Is completely at home with English.

Level 7. GOOD USER. Can cope in most situations in an English-speaking environment. Occasional mistakes do not prevent communication.

Level 5. MODEST USER. Manages to communicate, with difficuty and extra time. Often uses inaccurate or inappropriate language.

Level 3. LIMITED USER. Does not have a working knowledge of the language for dayto-day purposes, but better than an absolute beginner. Not much continuous communication.

Level 1. NON-USER. Has little or no English. 


\section{APPENDIX B}

\section{THE TEACHING OF THINKING}

\section{(Course Notes from Mrs B Capdevielle, January 1988)}

\section{OBJECTIVES OF TEACHING THINKING:}

To promote a reflection process by diminishing the rate of impulsion before the emission of judgements and opinions;

To learn to develop useful patterns of thinking for different types and levels of complexity of problem-solving situations;

To stimulate the organization of thoughts in order to facilitate an adequate handling of information;

To develop critical thinking;

To promote consciousness in the individual of his or her own capacities and of the social importance of one's work;

To increase self-esteem, trust in one's self and generation of self-promoting behaviours.

\section{THINKING SKILLS SELECTED FROM CORT 1, COGNITIVE RESEARCH}

\section{TRUST, E DE BONO (1986)}

P N I Positive, Negative and Interesting. The deliberate examination of an idea or situation in terms of its positive, negative and interesting aspects, instead of its immediate acceptance or rejection.

C A F Consider All Factors. The consideration and listing of all the factors involved in a situation, instead of taking into account only the most immediate.

F I P First Important Priorities. The determination of the importance of each aspect of a situation.

A G O Aims, Goals and Objectives. The definition and establishment of ends in a given situation.

C \& S Consequences and Sequels. The consideration of the outcomes in the immediate, short, medium and long term.

O P V Other People's View. The consideration of the points of view of all the people involved in a given situation. 


\section{APPENDIX C}

\section{INTERVIEW ASSESSMENT SCALE (CARROLL'S BANDS)}

Band

\begin{tabular}{|c|c|}
\hline 9 & $\begin{array}{l}\text { Expert speaker. Speaks with authority on a variety of topics. Can initiate, expand } \\
\text { and develop a theme. }\end{array}$ \\
\hline 8 & $\begin{array}{l}\text { Very good non-native speaker. Maintains effectively his own part of a discussion. } \\
\text { Initiates, maintains and elaborates as necessary. Reveals humour where needed } \\
\text { and responds to attitudinal tones. }\end{array}$ \\
\hline 7 & $\begin{array}{l}\text { Good speaker. Presents case clearly and logically and can develop the dialogue } \\
\text { coherently and constructively. Rather less flexible and fluent than Band } 8 \\
\text { performer but can respond to main changes of tone or topic. Some hesitation and } \\
\text { repetition due to a measure of language restriction but interacts effectively. }\end{array}$ \\
\hline 6 & $\begin{array}{l}\text { Competent speaker. Is able to maintain theme of dialogue, to follow topic switches } \\
\text { and to use and appreciate main attitude markers. Stumbles and hesitates at times } \\
\text { but is reasonably fluent otherwise. Some errors and inappropriate language but } \\
\text { these will not impede exchange of views. Shows some independence in discussion } \\
\text { with ability to initiate. }\end{array}$ \\
\hline 5 & $\begin{array}{l}\text { Modest speaker. Although gist of dialogue is relevant and can be basically } \\
\text { understood, there are noticeable deficiencies in mastery of language patterns and } \\
\text { style. Needs to ask for repetition or clarification and similarly to be asked for } \\
\text { them. Lacks flexibility and initiative. The interviewer often has to speak rather } \\
\text { deliberately. Copes but not with great style or interest. }\end{array}$ \\
\hline 4 & $\begin{array}{l}\text { Marginal speaker. Can maintain dialogue but in a rather passive manner, rarely } \\
\text { taking initiative or guiding the discussion. Has difficulty in following English at } \\
\text { normal speed; lacks fluency and probably accuracy in speaking. The dialogue is } \\
\text { therefore neither easy nor flowing. Nevertheless, gives the impression that he is in } \\
\text { touch with the gist of the dialogue even if not wholly master of it. Marked L1 } \\
\text { accent. }\end{array}$ \\
\hline 3 & $\begin{array}{l}\text { Extremely limited speaker. Dialogue is a drawn-out affair punctuated with } \\
\text { hesitations and misunderstanding. Only catches part of normal speech and unable } \\
\text { to produce continuous and accurate discourse. Basic merit is just hanging on to } \\
\text { discussion gist, without making major contribution to it. }\end{array}$ \\
\hline 2 & Intermittent speaker. No working facility; occasional, sporadic communication. \\
\hline $1 / 0$ & Non-speaker. Not able to understand and/or speak. \\
\hline
\end{tabular}

